The Journal of Laryngology \& Otology

http://journals.cambridge.org/JLO

Additional services for The Journal of Laryngology \& Otology:

Email alerts: $\underline{\text { Click here }}$

Subscriptions: $\underline{\text { Click here }}$

Commercial reprints: $\underline{\text { Click here }}$

Terms of use : $\underline{\text { Click here }}$

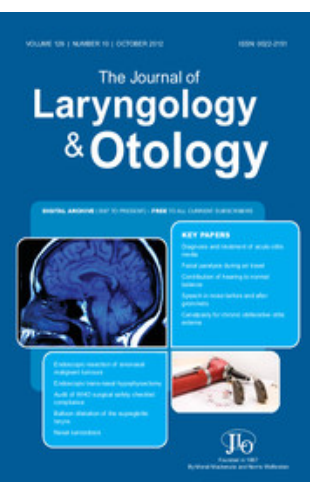

\title{
Bilateral parotid secondaries from primary bronchial carcinoid tumour
}

Michael G. Dilkes and Martin A. Birchall

The Journal of Laryngology \& Otology / Volume 105 / Issue 06 / June 1991, pp 489 - 490

DOI: 10.1017/S0022215100116391, Published online: 29 June 2007

Link to this article: http://journals.cambridge.org/abstract_S0022215100116391

How to cite this article:

Michael G. Dilkes and Martin A. Birchall (1991). Bilateral parotid secondaries from primary bronchial carcinoid tumour. The Journal of Laryngology \& Otology, 105, pp 489-490 doi:10.1017/S0022215100116391

Request Permissions : $\underline{\text { Click here }}$ 


\title{
Bilateral parotid secondaries from primary bronchial carcinoid tumour
}

\author{
Michael G. Dilkes, Martin A. Birchall (London)
}

\begin{abstract}
Three years following a right lower lobectomy for primary carcinoid tumour of the bronchus, a patient presented with bilateral parotid masses. On investigation, both these were shown to be carcinoid tumours, consistent with metastatic spread from the primary bronchial tumour. This unique case is presented together with a discussion of the diagnostic methods employed.
\end{abstract}

\section{Case report}

In 1984, a 64-year-old lady was found on routine chest X-ray, to have a $3 \mathrm{~cm}$ opacity in her right lower lobe. Investigation including rigid bronchoscopy, computerized tomography of the chest, liver and bone scans excluded any further disease and she duly underwent a lobectomy. Histology showed features typical of carcinoid tumour.

Three years later, the patient was being followed up in an ENT clinic for chronic otitis media, when a $3 \mathrm{~cm}$ left parotid swelling was discovered. Fine-needle aspiration and computerized tomographic (CT) scan were arranged, at which time she was found to have a similar mass on the right side. This too was aspirated.

The scan showed bilateral irregular deposits in the superficial parts of both parotid glands, extending deeply on the left (Fig. 1). Aspirates from each side showed features highly diagnostic of carcinoid tumour (Fig. 2), as described below. The microscopic appearances were identical with those of the earlier lung primary. Twenty four hour urine 5-hydroxyindoleacetic acid (5-HIAA) levels were normal.

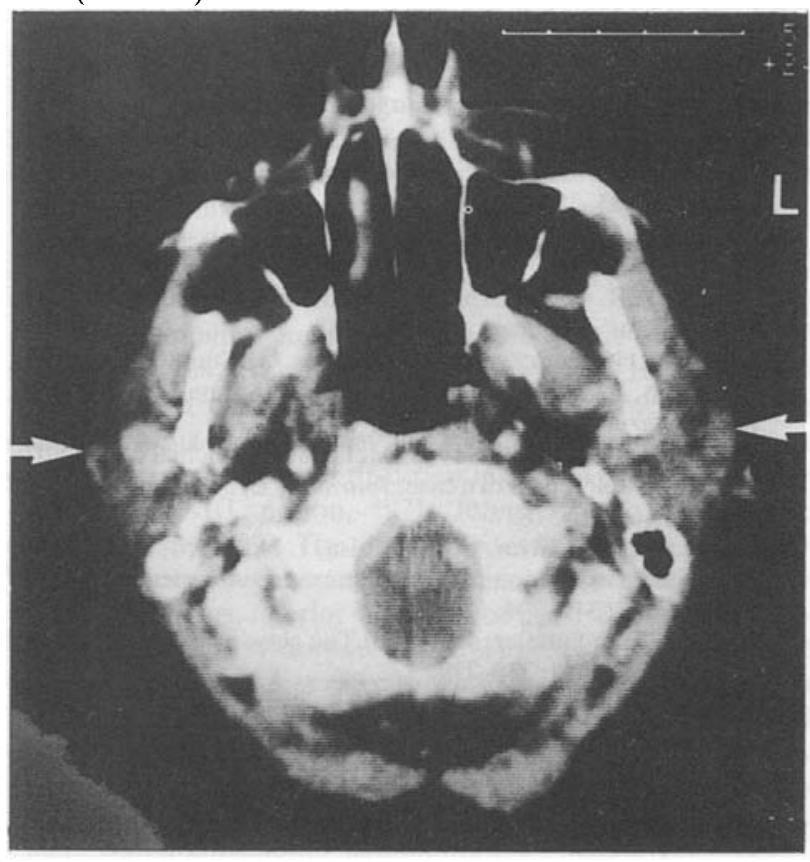

FIG. 1

Computerized tomogram showing bilateral parotid masses (arrowed), extending more deeply on the left.
Following conventional radiotherapy $(4,448 \mathrm{cGy})$ both lesions have undergone clinical and radiological regression. There has been no recurrence at one year.

\section{Discussion}

Carcinoid tumours are thought to arise from endocrine cells, particularly of appendix, rectum, small intestine, and lung (De Lellis et al., 1984). The tumours are classified according to their embryological origin: foregut, midgut and hindgut, with the category being extended more recently to cover extraintestinal neoplasms (Williams and Sandler, 1963). As part of the group of tumours known as APUDomas, they have the potential to secrete various physiologically-active peptides, especially serotonin.

Bronchial carcinoid tumours are particularly slow-growing and thus resection generally leads to an excellent prognosis (Martensson, H. et al., 1987). Malignancy is determined not by histological features, but by the appearance of secondaries which may occur up to ten years after successful treatment of the primary lesion (Bensch et al., 1965). Hence the delay of four years in this instance is by no means unusual.

Diagnosis in this case demonstrated the usefulness of fine needle aspiration biopsy (FNAB), which is used routinely in our department for parotid swellings. Of the last 32 parotid FNAB's performed, 19 ( 59 per cent) were diagnostic with a sensitivity of 78 per cent, specificity of 93 per cent, and complete concordance in 74 per cent of patients in whom paraffin section material was later obtained. These figures are similar to those in the larger reported series (Eneroth et al., 1970; Berg et al., 1986; Rodriguez et al., 1989). In addition to reliability, the technique is cheap, safe (Engzell et al., 1971), simple and avoids the risks of an operation, such as possible facial nerve damage in the reported case. The usefulness of CT scanning for parotid masses is well-established and complements the fine-needle findings (Berg et al., 1986; Cameron and Mann, 1989).

The electron microscopic appearances of the cytology obtained were highly specific for carcinoid tumour (Bensch et $a l ., 1965)$, showing uniform 2000 Angstrom, highly electronopaque granules, surrounded by a unit membrane, and with otherwise scanty organelles (Fig. 2). This was identical with the original bronchial specimen. Together with the clinical picture, this is convincing evidence that the case illustrated is an example of bilateral parotid secondaries from a bronchial carcinoid, a previously unreported event.

An alternative view would be that this represents multicentric disease. In Godwin's series, only 6 of 2837 reported carcinoids were multicentric, and these were confined to the small intestine. Hence, this appears less likely (Godwin, 1975). 


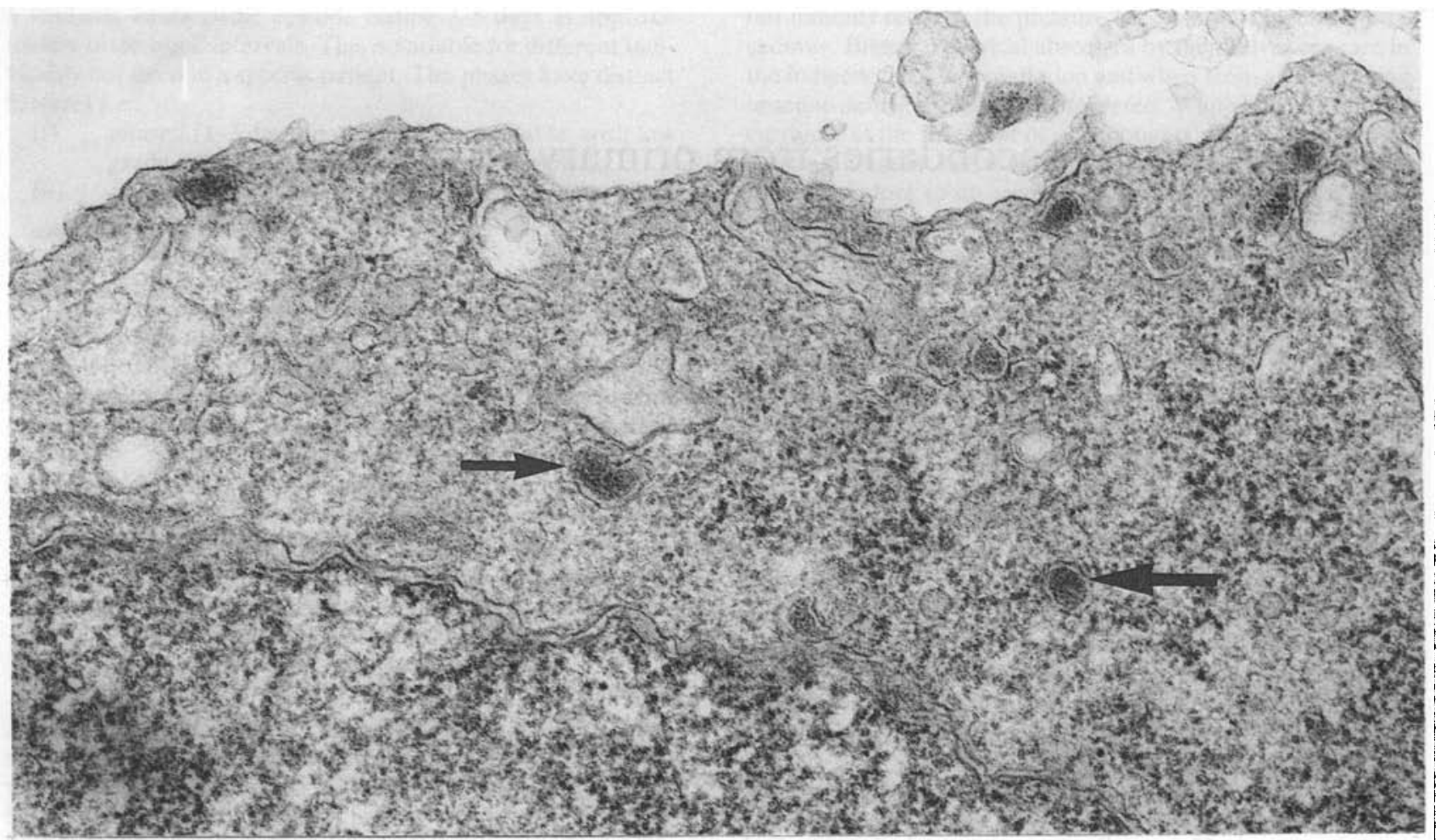

FIG. 2

Transmission electron micrograph from parotid aspirate, showing cellular features characteristic of carcinoid: highly electron-opaque core granules (arrowed) surrounded by a unit membrane and sparse organelles.

Metastases of bronchial carcinoids to the head and neck are very rare. There are only two cases documented in the literature: one to the mandible (Haggerty, 1987), and one to the soft palate (Mintz and Radecki, 1988). The parotid gland is a very uncommon site for metastases from a primary tumour that is not a squamous cell carcinoma (Bergersen et al., 1987).

In view of the patient's age, the hazardous nature of the surgery that would be necessary to remove these tumours, and the indolent nature of the disease, it was decided to refer her for a course of radiotherapy. Although carcinoid tumours are not thought to be very radiosensitive (De Lellis et al., 1984), a recent study (Abrams, 1987) reported an objective response to radiotherapy in 54 per cent of cases and complete regression in 23 per cent of cases. The response of the tumours in the above case is consistent with these findings.

\section{Acknowledgements}

The authors would like to thank Dr E. Martin-Bates of St Mary's Hospital Cytology Department, Mr N. D. Stafford, Consultant ENT Surgeon, and the Department of Medical Illustration of St Mary's Hospital for their help in preparing this report.

\section{References}

Abrams, R. A. (1987) Objective response of malignant carcinoid to radiation therapy. International Journal of Radiation, Oncology, Biology and Physics, 13: 869-873.

Bensch, K. G., Gordon, G. B., Miller, L. R. (1965) Electron microscopic and biochemical studies on the bronchial carcinoid tumour. Cancer, 18: 592-602

Berg, H. M., Jacobs, J. B., Kaufman, D., Reede, D. L. (1986) Correlation of fine-needle aspiration biopsy and CT scanning of parotid masses. Larynoscope, 96: 1357-1362.

Bergersen, P. J., Kennedy, P. J., Kneale, K. L. (1987) Metastatic tumours of the parotid gland. Australia and New Zealand Journal of Surgery, 57: 23-26.

Cameron, R. H., Mann, C. H. (1989) Fine-needle aspiration and computed tomographic scanning in the evaluation of parotid lesions. Ear Nose and Throat Journal, 86: 229-236.

De Lellis, R. A., Dayal, Y., Wolfe, H. J. (1984) Carcinoid tumours. Changing concepts and new perspectives. American Journal of Surgical Pathology, 8: 295-299.

Eneroth, C. M., Franzen, S., Zajicek, J. (1987) Cytologic diagnosis on aspirate from 1000 salivary tumours. Acta otolaryngologica, Supplement 224: 168-172.

Engzell, U., Esposti, P. L., Rubio, C. (1971) Investigation of tumour spread in connection with aspiration biopsy. Acta Radiologica, 10: 385-389.

Godwin, J. D. (1975) Carcinoid tumours. An analysis of 2837 cases. Cancer, 36: 560-569.

Haggerty, D. R. (1987) Bronchial carcinoid metastatic to the mandible. Military Medicine, 152: 161-162.

Martensson, H. , Bottcher, B., Hambraeus, G., Sundler, F., Willen, H., Nobin, A. (1987) Bronchial carcinoids: an analysis of 91 cases World Journal of Surgery, 11: 356-364.

Mintz, S. M., Radecki, C. (1988) Metastatic bronchial carcinoid of the soft palate: report of a case. Journal of Oral and Maxillofacial Surgery, 46: 516-518.

Rodriguez, H. P., Silver, C. E., Moisa, I. I., Chaco, M. S. (1989) Fine-needle aspiration of parotid tumours. American Journal of Surgery, 158: 342-344.

Williams, E. D., Sandler, M. (1963) The classification of carcinoid tumour. Lancet, 1:238-239.

Address for correspondence:

Mr M. A. Birchall, F.R.C.S.

ENT Department,

St Mary's Hospital,

Paddington,

London W2 $1 \mathrm{NY}$. 